\title{
Perioperative and short-term results of the surgical treatment of infective endocarditis
}

\author{
SL Moşteoru ${ }^{1 *}$, LM Lucuta' ${ }^{1}$ M Gaspar ${ }^{1,2}$, H Feier ${ }^{1,2}$ \\ From International Conference for Healthcare and Medical Students 2011 \\ Dublin, Ireland. 4-5 November 2011
}

\begin{abstract}
Introduction
Infective endocarditis is defined as the infection of the endocardial surface of the heart, which may include one or more heart valves or the mural endocardium. It results in severe valvular insufficiency, which may lead to congestive heart failure, and myocardial abscesses. One of the most feared complications is thromboembolism, through infected emboli. The purpose of this paper is to assess the perioperative and short term results of the IInd Cardiovascular Surgery Department in the treatment of infective endocarditis during a three year period, from January the first, 2002 to September the first, 2005.
\end{abstract}

\section{Methods}

We conducted a study on 31 patients operated upon during this timeframe. They represent $0.81 \%$ of the total number of 3795 surgical procedures performed in our clinic. $83.87 \%$ were male, with a mean age of 47.41 years. Eighteen (18/31, $58.06 \%$ ) were acute cases, out of which $29,03 \%(9 / 31)$ had the pathogenic agent identified by hemocultures and culture of the explanted valves. Three patients presented preoperative peripheral embolic events (9.67\%). The aortic valve was affected in $74.19 \%$ cases (23/31), the mitral valve in $41.93 \%(13 / 31)$ whereas there was a single tricuspid valve lesion $(3.22 \%, 1 / 31)$. Three of these cases were redo procedures $(9.67 \%)$.

\section{Results}

There were 35 valve replacements performed, 2 associated tricuspid plasties and two patients benefited from associated procedures: triple coronary artery bypass grafting and ascending aortic replacement. One patient presented a false aneurysm of the aortic root. The prosthesis used were mechanical $(23 / 31,74.19 \%)$, biological $(6 / 31$, $19.35 \%)$, homograft $(1 / 31,3.22 \%)$ or autograft $(1 / 31$,

"Victor Babeş" University of Medicine and Pharmacy, Timişoara, Romania Full list of author information is available at the end of the article
$3.22 \%$ ). The operative ( $<30$ days) mortality was $3.22 \%$ (a single patient expired). The mean follow up period was 15.708.54 months. Global survival at 1,6 and 12 months was $95.654 .25 \%$.

\section{Conclusions}

Infective endocarditis is a severe and potentially lethal disease but if a proper management is observed, there is a strong determinant for survival as proved by our study where the surgical treatment offers a short term survival which is not different from the one in the general population.

\section{Author details}

"'Victor Babeş" University of Medicine and Pharmacy, Timişoara, Romania. ${ }^{2}$ Timişoara Institute of Cardiovascular Medicine, IInd Cardiovascular Surgery Department, Romania.

Published: 9 July 2012

doi:10.1186/1753-6561-6-S4-P5

Cite this article as: Moşteoru et al:: Perioperative and short-term results of the surgical treatment of infective endocarditis. BMC Proceedings 2012 6(Suppl 4):P5.

Submit your next manuscript to BioMed Central and take full advantage of:

- Convenient online submission

- Thorough peer review

- No space constraints or color figure charges

- Immediate publication on acceptance

- Inclusion in PubMed, CAS, Scopus and Google Scholar

- Research which is freely available for redistribution 